\title{
Evaluation of the validity of the Psychology Experiment Building Language tests of vigilance, auditory memory, and decision making
}

Brian Piper, Shane T Mueller, Sara Talebzadeh, Min Jung Ki

Background. The Psychology Experimental Building Language (PEBL)

http://pebl.sourceforge.net/ test battery is a popular application for neurobehavioral investigations. This study evaluated the correspondence between the PEBL and the nonPEBL versions of four executive function tests. Methods. In one cohort, young-adults ( $\mathrm{N}=$ 44) completed both the Conner's Continuous Performance Test $\left({ }_{c} C P T\right)$ and the PEBL CPT ${ }_{\mathrm{P}} \mathrm{CPT}$ ) with the order counter-balanced. In a second cohort, participants ( $\mathrm{N}=47$ ) completed a non-computerized (Wechsler) and a computerized (PEBL) Digit Span $\left({ }_{w} \mathrm{DS}\right.$ or pDS) both Forward and Backward. Participants also completed the Psychological Assessment Resources or the PEBL versions of the lowa Gambling Task ( ${ }_{\mathrm{PAR}} \mathrm{IGT}$ or ${ }_{\mathrm{PEBL}} \mathrm{IGT}$ ). Results. The between-test correlations were moderately high (reaction time $r=0.78$, omission errors $r=0.65$, commission errors $r=0.66$ ) on the CPT. DS Forward was significantly greater than DS Backward on the ${ }_{w} \mathrm{DS}(p<.0005)$ and the ${ }_{\mathrm{p}} \mathrm{DS}(p<.0005)$. The total ${ }_{w} \mathrm{DS}$ score was moderately correlated with the ${ }_{\mathrm{p}} \mathrm{DS}(r=0.56)$. The ${ }_{\mathrm{PAR}} \mathrm{IGT}$ and the PEBLIGTS showed a very similar pattern for response times across blocks, development of preference for Advantageous over Disadvantageous Decks, and Deck selections. However, the amount of money earned (score - loan) was significantly higher in the ${ }_{\text {PEBL }}$ IGT during the last Block. Conclusions. These findings are broadly supportive of the criterion validity of the PEBL measures of sustained attention, short-term memory, and decision making. Select differences between workalike versions of the same test highlight how detailed aspects of implementation may have more important consequences for computerized testing than has been previously acknowledged. 


\section{Evaluation of the Validity of the Psychology Experiment Building Language Tests of}

\section{Vigilance, Auditory Memory, and Decision Making}

Brian J. Piper ${ }^{a b c}$, Shane T. Mueller ${ }^{\mathrm{d}}$ Sara Talebzadeh ${ }^{\mathrm{e}}$, \& Min Jung Ki ${ }^{\mathrm{b}}$

aNeuroscience Program, Bowdoin College, Brunswick, ME 04011 USA

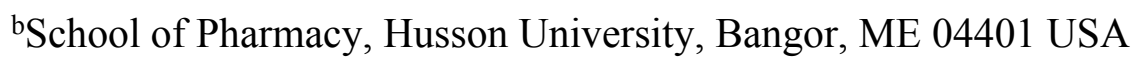

'Department of Psychology, Willamette University, Salem, OR 97301 USA

dDepartment of Cognitive and Learning Sciences, Michigan Technological University, Houghton, MI 49931 USA

eDepartment of Biology, Husson University, Bangor, ME 04401 USA

(1)

(n)

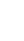

(1)

Corresponding Author:

Brian J. Piper, Ph.D.

255 Main Street

Department of Psychology \& Neuroscience Program

Bowdoin College

Brunswick, ME 04001

psy391@gmail.com; bpiper@bowdoin.edu 
40

41

42

43

44 Background. The Psychology Experimental Building Language (PEBL)

\section{Abstract}

http://pebl.sourceforge.net/ test battery is a popular application for neurobehavioral versions of four executive function tests.

Methods. In one cohort, young-adults $(\mathrm{N}=44)$ completed both the Conner's Continuous second cohort, participants $(\mathrm{N}=47)$ completed a non-computerized (Wechsler) and a Task (PARIGT or ${ }_{\text {PEBL }}$ IGT). moderately correlated with the ${ }_{\mathrm{P}} \mathrm{DS}(r=0.56)$. The ${ }_{\mathrm{PAR}} \mathrm{IGT}$ and the ${ }_{\mathrm{PEBL}}$ IGTs showed a very - loan) was significantly higher in the ${ }_{\mathrm{PEBL}}$ IGT during the last Block.

Conclusions. These findings are broadly supportive of the criterion validity of the PEBL investigations. This study evaluated the correspondence between the PEBL and the non-PEBL Performance Test $\left({ }_{\mathrm{C}} \mathrm{CPT}\right)$ and the PEBL CPT $\left({ }_{\mathrm{P}} \mathrm{CPT}\right)$ with the order counter-balanced. In a computerized (PEBL) Digit Span ( ${ }_{w} \mathrm{DS}$ or $\left.{ }_{\mathrm{P}} \mathrm{DS}\right)$ both Forward and Backward. Participants also completed the Psychological Assessment Resources or the PEBL versions of the Iowa Gambling

Results. The between-test correlations were moderately-high (reaction time $r=0.78$, omission errors $r=0.65$, commission errors $r=0.66$ ) on the CPT. DS Forward was significantly greater than DS Backward on the ${ }_{\mathrm{W}} \mathrm{DS}(p<.0005)$ and the ${ }_{\mathrm{P}} \mathrm{DS}(p<.0005)$. The total ${ }_{\mathrm{W}} \mathrm{DS}$ score was similar pattern for response times across blocks, development of preference for Advantageous over Disadvantageous Decks, and Deck selections. However, the amount of money earned (score measures of sustained attention, short-term memory, and decision making. Select differences between workalike versions of the same test highlight how detailed aspects of implementation 
64 may have more important consequences for computerized testing than has been previously 65 acknowledged. 


\section{INTRODUCTION}

67 An increasingly large collection (>100) of classic and novel clinical psychology and behavioral 68 neurology tests have been computerized and made freely available (http://pebl.sf.net) over the

69 past decade. The latest version of Psychology Experiment Building Language (PEBL) test

70 battery (Mueller, 2012, 2015; Mueller \& Piper, 2014; Piper et al. 2015a) was downloaded more

71 than 21,000 times in 2015 and use continues to increase (Fox et al. 2013; Lipnicki et al., 2009a,

72 2009b; Piper, 2010). The PEBL tests have been employed in studies of traumatic brain injury

73 (Danckert et al., 2011), behavioral pharmacology (Aggarwal et al., 2011; Lyvers \& Tobias-

74 Webb, 2010), aging (Clark \& Kar, 2011; Piper et al. 2012), Parkinson's disease (Peterson, et al.,

75 2015) and behavioral genetics (Wardle et al. 2013; González-Giraldo et al., 2014) by

76 investigators in developed and developing countries, and the tests have been administered in

77 many languages. A key step in PEBL battery development is to evaluate criterion validity (i.e.,

78 the extent to which its dependent measures predict other existing measures) by determining

79 whether performance on PEBL tests is similar to the established versions of the tests. Although

80 the PEBL tests were developed based on the method sections of the peer reviewed literature, this

81 direct comparison is important because some potentially important procedural details may have

82 been omitted, described ambiguously, or misinterpreted.

83 Four tests were selected for the present report for comparison between the PEBL and

84 non-PEBL (i.e. established) versions: the PEBL Continuous Performance Test (CPT), Digit Span

85 Forward (DS-F), DS Backward (DS-B), and the Iowa Gambling Task (IGT). These tests were

86 chosen because they assess theoretically important constructs (vigilance, attentional capacity,

87 short-term memory, and decision making), have an extensive history, and their neural substrates 
88 have been examined in lesion and neuroimaging studies. Each of these measures is described in

89 more detail below.

90 Continuous Performance Test (CPT)

91 CPTs have an extensive history and exist in multiple forms (Mackworth, 1948; Rosvold,

92 Mirsky et al., 1956; Anderson et al., 1969; Earle-Boyer et al., 1991; Greenberg \& Waldman,

93 1993; Dougherty, Marsh, \& Mathias, 2002; Riccio et al., 2002). These tests require participants

94 to maintain vigilance and respond to the presence of a specific stimulus within a set of

95 continuously presented distracters. A key quality of a CPT is that, rather than being a series of

96 trials that each require a response; a CPT is presented as a continuous series of stimuli whose

97 timing does not appear to depend on the speed or presence of a response, and so it represents a

98 continuous mental workload that has been used to assess vigilance, alertness, attention, and

99 related concepts. The CPT, version II, of Conners and colleagues (hence-forth ${ }_{\mathrm{C}} \mathrm{CPT}$ ) has been

100 widely used as a neuropsychological instrument to measure attention in children and adults

101 (Conners, 2004; Piper, et al., 2010, 2011). The fourteen minute ${ }_{\mathrm{C}} \mathrm{CPT}$ involves responding to

102 target letters (letters A - S presented for 1, 2, or $4 \mathrm{sec}$ each) and inhibiting responses to foils (the

103 letter X). Dependent measures include response times (RT), the variability of RT, the absence of

104 response to target stimuli (omission errors), and responses to the foil (commission errors). There

105 is some debate regarding the utility of the ${ }_{\mathrm{C}} \mathrm{CPT}$ to aid in a diagnosis of Attention Deficit

106 Hyperactivity Disorder (ADHD) (Cohen \& Shapiro, 2007; McGee, Clark, \& Symons, 2000).

107 Overall, the strengths of this instrument are its objectivity, simplicity, brevity, a sizable

108 normative sample (Conners \& Jeff, 1999; Homack \& Riccio, 2006), and it has been shown to be

109 sensitive to psychostimulants used to treat attention disorders (Solanto et al., 2009). In addition, 
110 the neural substrates of vigilance have been characterized and involve a network that includes the

111 prefrontal, frontal, and parietal cortex and the striatum (Ogg et al., 2008; Riccio, et al., 2002).

112 Digit Span Forward and Backward (DS-F and DS-B)

113 DS type tests are found in the Wechsler assessments as well as in other

114 neuropsychological batteries. A string of numbers is presented (e.g. 7, 1, 6 at a rate of one digit

115 per second) and the participant either repeats them in the same (DS-F) or the reverse (DS-B)

116 sequence. Although DS-F and DS-B are procedurally similar, and they are sometimes viewed as

117 simple short-term memory tasks (St. Clair-Thompson \& Allen, 2013), the former is sometimes

118 treated as a measure of 'pure storage' whereas the latter is viewed as involving more executive

119 control and thus considered a "working memory" task (Lezak et al., 2012). DS-B induces greater

120 activity in the prefrontal cortex than DS-F (Keneko et al., 2011).

121 A direct comparison of DS by mode of administration revealed lower DS Forward and

122 Backward when completed over the telephone with voice recognition as compared to in-person

123 administration (Miller et al., 2013). However, a moderate correlation $(\mathrm{r}=.53)$ in DS total was

124 identified with traditional and computerized administration (Paul et al., 2005).

125 Iowa Gambling Test (IGT)

126

127

Bechara and colleagues at the University of Iowa College of Medicine developed a novel

128 task to quantify abnormalities in decision making abilities. Originally, what became known as

129 the Iowa Gambling Task (IGT) involved selecting cards from four physical decks of cards. Each

130 deck had a different probability of wins versus losses. Two decks are Disadvantageous and two

131 are Advantageous, because some deck selections will lead to losses over the long run, and others

132 will lead to gains. Neurologically intact participants were reported to make the majority (70\%) of

133 one-hundred selections from the Advantageous (C \& D) decks. In contrast, patients with lesions 
134 of the prefrontal cortex showed the reverse pattern with a strong preference for the

135 Disadvantageous (A \& B) decks (Bechara et al., 1994, although see Buelow \& Suhr, 2009;

136 Steingroever, et al., 2013). However, another research team, employing a gambling task that

137 they programmed, determined that college-aged adults showed a response pattern that is very

138 similar to patients with frontal lesions (Caroselli, et al., 2006). Similarly, the median response

139 among a moderate sized sample $(\mathrm{N}=39)$ of college students from the southwestern United

140 States was to make more select more selections from Disadvantageous than Advantageous Decks

141 on the Psychological Assessment Resources (PAR) version of the IGT (Piper, et al. 2015b). IGT

142 type tasks have become increasingly popular for research purposes to examine individual

143 differences in decision making including in pathological gamblers, substance abusers, ADHD,

144 and in other neurobehavioral disorders (Buelow \& Suhr, 2009; Verdejo-Garcia, et al., 2007).

145 One key characteristic of the IGT is that there is substantial carryover of learning with repeated

146 administrations in normal participants (Bechara, et al., 2000a; Bull, et al., 2015; Fernie \&

147 Tumney, 2006; Piper et al. 2015a; Verdejo-Garcia et al. 2007). Bechara, in conjunction with

148 PAR, distributes a computerized version of the IGT (Bechara, 2007). The IGT is also one of the

149 more widely employed tests in the PEBL battery (Bull, et al., 2015; Hawthorne et al., 2011;

150 Lipnicki, et al., 2009a, 2009b; Mueller \& Piper, 2014) and so itself has been used in many

151 different contexts. Many variations on IGT procedures have been developed over the past two

152 decades. The ${ }_{\text {PEBL }}$ IGT employs consistent rewards and punishment (e.g. - $\$ 1,250$ for each

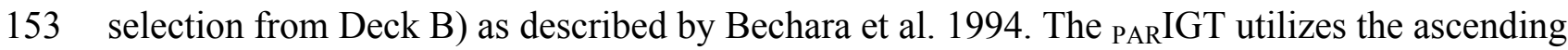

154 schedule of rewards and punishments (e.g. - $\$ 1,250$ for early deck selections and decreasing by

$155 \$ 250$ increments) (Bechara et al. 2000b). 
156 The primary objective of this report was to determine the similarity between the PEBL

157 and non-PEBL versions of these executive function measures. A common strategy to test

158 development would be to administer both the PEBL and non-PEBL versions to tests to

159 participants with the order counter-balanced. Interestingly, a prior study administered the PEBL

160 digit span forward, a continuous performance test with some procedural similarities to the

161 TOAV, and the IGT to young-adults twice with a two-week inter-test interval and identified

162 moderate to high test-retest correlations on measures of attention (Spearman rho $=.69$ to .72$)$ and

163 digit-span $($ rho $=.62)$ while the total money earned on the IGT was less consistent $($ rho $=.22)$

164 (Piper et al. 2015). These findings suggest that the approach of administering both PEBL and

165 non-PEBL versions and examining correlations across platforms might be viable for DS and the

166 CPT but not the IGT. The IGT dataset was also used to critically examine the sensitivity of the

167 IGT to identify clinically meaningful individual differences in decision making abilities. The

168 commercial distributors of an IGT purport that neurologically intact and those that have suffered

169 a brain insult should score quite differently. If "normal" college students completing the IGT

170 showed a pattern of responding that would be labeled impaired (as has been shown earlier;

171 cf.Caroselli, et al., 2006, Piper et al. 2015b), these findings would challenge the construct

172 validity of this measure. Participants in this study completed PEBL and/or non-PEBL versions

173 of the same tests. Correlations across platforms were determined for the CPT and DS and the

174 pattern of responses were evaluated for each IGT. Where applicable, intra-test correlations were

175 also examined as this is one criteria used to evaluate test equivalence (Bartram, 1994). 
Participants. The participants $(\mathrm{N}=44 ;$ Age $=18-24$, Mean $=18.7 \pm 0.2 ; 68.2 \%$ female;

23.9\% non-white; $7.3 \%$ ADHD) were college students receiving course credit in the CPT study.

A separate cohort $(\mathrm{N}=47 ;$ Age $=18-34$, Mean $=18.8 \pm 0.3 ; 59.6 \%$ female; $14.9 \%$ non-white;

$10.6 \%$ ADHD) of college students completed the DS/IGT study and also received course credit.

Willamette University (first cohort) or the University of Maine, Orono (second cohort).

Participants were tested individually with an experimenter in the same room. Each participant completed an informed consent and a short demographic form which included items about sex, age, whether they had been diagnosed by a medical professional with ADHD. Next, the first cohort completed either the ${ }_{\mathrm{P}} \mathrm{CPT}$ or Version II of the ${ }_{\mathrm{C}} \mathrm{CPT}$, including the two-minute practice trial, with the order counter-balanced on desktop computers running Windows XP and not connected to the internet. As data collection for each CPT takes 14 minutes and is intentionally monotonous, the PEBL Tower of London (Piper et al. 2012) was completed between each CPT

191 as a brief $(\approx 5 \mathrm{~min})$ distractor task. The ${ }_{\mathrm{P}} \mathrm{CPT}$ was modified from the default in PEBL version

193 The instructions of the ${ }_{\mathrm{P}} \mathrm{CPT}$ were:

You are about to take part in an experiment that involves paying attention to letters on a screen. It will take about 14 minutes. You will see letters presented on a screen quickly. Your goal is to press the spacebar as fast as possible after each letter, except if the letter is an ' $\mathrm{X}$ '. DO NOT RESPOND to $\mathrm{X}$ stimuli.

foils $(\mathrm{X})$ were presented with an inter-stimulus interval of 1,2, or 4 seconds. The primary dependent measures were the RT on correct trials in ms, the standard deviation (SD) of RT, 
202 omission and commission errors. The ${ }_{\mathrm{P}} \mathrm{CPT}$ source code is also at:

203 https://github.com/stmueller/pebl-custom ).

204 The second cohort completed a short demographic form (described above) followed by

205 the PEBL and non-PEBL tasks (DS-F, DS-B, and IGT) with the order counterbalanced across

206 testing sessions. PEBL, version 0.14, was installed on Dell laptops (Latitude E6410 and 6420)

207 running Windows 7. Both laptops were connected to Dell touchscreen monitors ( 20" Touch

208 model number 0MFT4K) which were used for selecting responses on the IGT.

209 The Wechsler DS (wDS) consists of two trials for each number of items each read aloud

210 by the experimenter at a rate of one per second beginning with two items. Discontinuation

211 occurred when both trials for a single number of items were answered incorrectly. The maximum

212 total score for DS Forward and Backward is sixteen and fourteen, respectively. The PEBL Digit

213 Span $\left({ }_{\mathrm{p}} \mathrm{DS}\right)$ source code was modified slightly from the default version so that stimuli were

214 presented via headphones (one per 1,000 ms) but not visually (PEBL script available at:

215 https://github.com/stmueller/pebl-custom ) in order to be more similar to the WDS. Two trials

216 were completed for each number of items starting with three items. Digit stimuli were generated

217 randomly such that each sequence contained no more than one of each digit. Discontinuation

218 occurred when both trials for a single number of items were answered incorrectly. An important

219 methodological difference between the ${ }_{\mathrm{W}} \mathrm{DS}$ and the ${ }_{\mathrm{P}} \mathrm{DS}$ involves how responses are collected.

220 The traditional ${ }_{\mathrm{W}} \mathrm{DS}$ involves oral responses coded by the experimenter. The ${ }_{\mathrm{P}} \mathrm{DS}$ involves typed

221 input with the response sequence visible on-screen as it is made. Furthermore, blank entries are

222 permitted and participants have the ability to delete erroneous responses (see supplemental

223 materials for the source code and task instructions). 
225 headphones. The administration instructions were shown and read/paraphrased for the participant

226 (Bechara et al. 2000a, Bechara, 2007) and the default settings were used. The ${ }_{P E B L}$ IGT was also

227 administered with the order counterbalanced. Because others have identified pronounced practice

228 effects with the IGT (Bechara et al. 2000a; Bull, et al., 2015; Birkett et al., 2015; Fontaine, Piper,

229 Mueller, \& Coane, 2015; Verdejo-Garcia et al. 2007) and we found that the amount earned

230 increase by $106.3 \%$ on the second administration (Piper et al. 2015a), only data from the IGT

231 administered first was examined. The ${ }_{\text {PEBL }}$ IGT has modifications contributed by P. N. Bull

232 (supplemental materials at: https://github.com/stmueller/pebl-custom) and is a more refined

233 version of the task than has been used previously (Hawthorne et al., 2011; Lipnicki et al., 2009a,

234 2009b; Piper et al. 2015b). If scores go below zero, participants will receive a second \$2,000

235 loan. Importantly, the ${ }_{\text {PEBL }}$ IGT is based on the procedures described in Bechara et al. 1994 while

236 the ${ }_{\text {PAR }}$ IGT is based on those described in great detail in Bechara et al. 2000b. The instructions

237 are $14 \%$ shorter on the ${ }_{\mathrm{PEBL}}$ IGT but perhaps the largest procedural difference is the negative

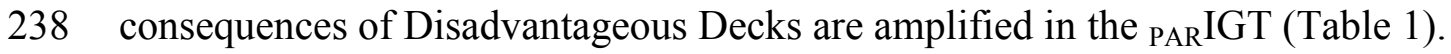

239 Statistical analyses: The overall data analytic strategy to evaluate test validity was

240 tailored to the characteristics of each test. For the CPT and DS, this involved calculating intra-

241 test correlations (Bartram, 1994), cross-test correlations ( $\mathrm{r}=.30$ to .70 are moderate, $\mathrm{r}>.70$ are

242 high), and comparing means across platforms. Similar intra-test correlations, high and significant

243 cross-test correlations, and small/non-significant differences in means are supportive of test

244 similarity. Due to substantial practice effects on the IGT (Bull, et al., 2015; Fontaine et al. 2015;

245 Piper et al. 2015a), and that not all of the second IGT tests were completed, due to participant

246 time limitations data from the second IGT was not examined and analyses instead focused on 
247 determining the response patterns within the first test and whether they were similar across

248 platforms. The standardized (age and sex corrected) scores (percentiles) of the sample were

249 reported for the CCPT and PARIGT. The ${ }_{\mathrm{P}} \mathrm{CPT}$ output text files were imported into Excel and all

250 analyses were subsequently conducted using Systat, version 13.0. The distribution on some

251 measures (e.g. RT), were, as anticipated, non-normal, therefore both Pearson ( $\left.\mathrm{r}_{\mathrm{P}}\right)$ and Spearman

252 rho $\left(\mathrm{r}_{\mathrm{S}}\right)$ correlation coefficients were completed as was done previously (Piper et al. 2015a). As

253 the ${ }_{\mathrm{P}} \mathrm{CPT}$ default settings express the variability in RT slightly differently (SD) than the $\mathrm{CCPT}$

254 (SE), the PEBL output was converted to the $\mathrm{SE}$ according to the formula $\mathrm{SD} /(\mathrm{N}-1)^{0.5}$ where $\mathrm{N}$

255 is the total number of correct trials across the three inter-trial intervals. Differences in intra-test

256 correlations (e.g. omission by commission errors) between the ${ }_{\mathrm{P}} \mathrm{CPT}$ and ${ }_{\mathrm{C}} \mathrm{CPT}$ were evaluated

257 with a Fisher $r$ to $Z$ transHighlightion (http://vassarstats.net/rdiff.html ). The 95\% Confidence

258 Interval (CI) of select Pearson correlations was determined (http://vassarstats.net/rho.html ) and

259 the effect size of group differences was expressed in terms of Cohen's $d$

260 (http://www.cognitiveflexibility.org/effectsize/). As the ${ }_{\mathrm{w}} \mathrm{DS}$ starts at an easier level (2 digits)

261 than the ${ }_{\mathrm{P}} \mathrm{DS}$ (3 digits), two additional points were added to each (Forward and Backward) ${ }_{\mathrm{P}} \mathrm{DS}$

262 for comparison purposes. The primary dependent measure on the IGT was Deck selections but

263 Response Times on each Block of twenty-trials and the compensation (score minus loan) for

264 each trial was also documented. The NET was calculated as Advantageous minus

265 Disadvantageous Deck selections. Mean data are presented with the standard error of the mean

266 (SEM) and $p<.05$ considered statistically significant although statistics that met more

267 conservative alpha levels (e.g. .0005) are noted. 


\section{RESULTS}

270

271

Continuous Performance Test (CPT)

272

Substantial individual differences in sustained attention were observed in this sample.

273 The percentiles (+ SEM) for each ${ }_{\mathrm{C}}$ CPT measure are shown in Table 2.

274 Mean reaction time on correct trials was slightly (by $12 \mathrm{~ms}$ ) shorter on the PCPT, which 275 was statistically significant ${ }_{\mathrm{C}} \mathrm{CPT}=327.1+6.5$, Kurtosis $=3.82,{ }_{\mathrm{P}} \mathrm{CPT}=315.2+4.7$, Kurtosis $276=0.30, t(43)=2.91, p<.01, d=.48)$. The difference in the SE of RT was clearly different $\left({ }_{\mathrm{C}} \mathrm{CPT}\right.$ $277=5.3 \pm 0.4$, Kurtosis $=6.22,{ }_{\mathrm{P}} \mathrm{CPT}=3.3 \pm 0.5$, Kurtosis $\left.=37.86, t(43)=5.60, p<.0005, d=.87\right)$

278 but there was no difference for omission errors $\left({ }_{\mathrm{C}} \mathrm{CPT}=2.6 \pm 0.6\right.$, Kurtosis $=6.41,{ }_{\mathrm{P}} \mathrm{CPT}=2.3 \pm$ 2790.7$, Kurtosis $=26.00, t(43)=0.51, p=.61)$ or commission errors $\left({ }_{\mathrm{C}} \mathrm{CPT}=18.1 \pm 1.1,{ }_{\mathrm{P}} \mathrm{CPT}=\right.$ $28017.3 \pm 1.0, t(43)=0.96, p=.34)$.

281 The inter-test correlations were generally satisfactory. The correlation was excellent for 282 reaction time $\left(r_{P}(42)=+.78,95 \% \mathrm{CI}=.63\right.$ to $.87 ; r_{S}(42)=+.80, p<.0005$, Figure $\left.1 \mathrm{~A}\right)$. The 283 cross-platform association for reaction time variability was also moderate $\left(r_{P}(42)=+.66, p<.01\right.$, $28495 \% \mathrm{CI}=.46$ to $\left..80 ; r_{S}(42)=+.27, p=.076\right)$ but this association should be viewed with caution 285 as removal of one extreme score $(15.9$, Grub's test $=4.18, p<.01 ; 23.3$, Grubs test $=6.26, p<$ $286.01)$ reduced this correlation considerably $\left(r_{P}(41)=+.20,95 \% \mathrm{CI}=-.11\right.$ to $+.47, p=.19$;

287 Supplementary Figure 1$)$. Omission errors $\left(r_{P}(42)=+.65,95 \% \mathrm{CI}=.44\right.$ to $.79, p<.0005, r_{\mathrm{S}}(42)$ $288=+.31, p<.05)$ and commission errors $\left(r_{\mathrm{P}}(42)=+.66,95 \% \mathrm{CI}=.45\right.$ to $.80, r_{\mathrm{S}}(42)=+.66, p$ $289<.0005)$ showed good correlations across tests (Figure 1B \& 1C). 
An analysis of the intra-test Spearman correlations among the variables of each test was

291 also conducted (Table 3). Several significant correlations were identified. However, with the

292 exception of a trend for the RT SE $(p=.055)$, the correlations did not differ across tests.

293 Digit Span (DS)

294 Figure $2 \mathrm{~A}$ shows the anticipated higher score for Forward $(10.0 \pm 0.3$, Min $=6, \operatorname{Max}=$

295 13) relative to Backward $(6.3 \pm 0.3, \operatorname{Min}=3, \operatorname{Max}=11)$ on the ${ }_{\mathrm{w}} \mathrm{DS}$. The correlation between

296 Forward and Backward was moderate $\left(r_{P}(45)=.43,95 \% \mathrm{CI}=.16\right.$ to $.64, p<.005 ; r_{S}(45)=.41, p$ $297<.005)$.

298 Figure $2 \mathrm{~A}$ also depicts an elevated score for Forward $(10.5 \pm 0.4, \operatorname{Min}=3, \operatorname{Max}=15)$

299 compared to Backward $(8.2 \pm 0.3, \operatorname{Min}=4, \operatorname{Max}=12, t(46)=5.10, p<.0005)$ for the ${ }_{\mathrm{P}} \mathrm{DS}$. The

300 correlation between Forward and Backward was not significant $\left(r_{P}(45)=.22,95 \% \mathrm{CI}=-.07\right.$ to

$\left.301.48, p>.10 ; r_{S}(45)=.28, p=.054\right)$. The ${ }_{\mathrm{P}} \mathrm{DS}-\mathrm{B}$ was significantly higher than ${ }_{\mathrm{W}} \mathrm{DS}-\mathrm{B}(t(46)=$

$3026.43, p<.0005$ ), which is likely to stem from using a visual/manual response entry rather than 303 the verbal mode used in the ${ }_{\mathrm{W}} \mathrm{DS}-\mathrm{B}$.

304 The correlation between computerized and non-computerized DS was intermediate for

305 Forward $\left(r_{P}(45)=.42,95 \%\right.$ CI .15 to $\left..63, p<.005 ; \mathrm{r}_{\mathrm{S}}(45)=.45, p<.005\right)$ and Backward $\left(r_{P}(45)\right.$

$306=.49,95 \% \mathrm{CI}=.24$ to $\left..68, p<.001 ; r_{S}(45)=.467, p<.001\right)$. Figure $2 \mathrm{~B}$ shows the association

307 between the DS total (Forward + Backward) across test modalities was moderate $\left(r_{S}(47)=.51, p\right.$ $308<.0005)$

310 Iowa Gambling Task (IGT)

311 Data-analysis was completed by examining each test separately and then comparing

312 across platforms. The NET 1 to 5 percentile score was $38.0 \pm 4.4(\mathrm{Min}=5, \mathrm{Max}=90)$ on the 
313 PAR IGT. The standardized $\left(\mathrm{T}_{50}\right)$ score was 47.2 $\pm 1.5(\mathrm{Min}=34.0, \mathrm{Max}=63.0)$ which was non-

314 significantly lower than the normative mean of 50 (one sample $t(23)=1.91, p=.069$ ). A

315 repeated measures ANOVA on Response Times revealed a main effect of Block $(\mathrm{F}(1.81,41.69)$

$316=21.10, \mathrm{p}<.0005)$ Response Times showed a clear decrease over the course of the session with

317 shorter times on Block $2(t(23)=4.49, p<.0005)$, Block $3(t(23)=5.93, p<.0005)$, Block 4

$318(t(23)=5.42, p<.0005)$ and Block $5(t(23)=5.07, p<.0005)$ relative to Block 1 (Figure $3 \mathrm{~A})$.

319 Responses on the first Block showed a trend favoring Disadvantageous over Advantageous

320 Decks $(t(23)=1.90, p=.07)$ with the reverse pattern on the last Block (Figure 3C). Similarly,

321 there was a trend toward greater Advantageous selections on Block $5(11.0 \pm 0.9)$ compared to

322 Block $1(t(23)=1.83, p=.081)$. Across all Blocks, participants made fewer selections from

323 Deck A' compared to Deck B' $(t(23)=8.98, p<.0005)$, Deck C' $(t(23)=3.48, p \leq .002)$ or

324 Deck D' $(t(23)=3.65, p \leq .001)$. Participants made more selections from Deck B' compared to

325 Deck C' $(t(23)=2.79, p \leq .01)$ or Deck D' $(t(23)=2.72, p<.02$, Figure 3E). Almost half

$326(45.8 \%)$ of participants made more selections from Disadvantageous (C' $\left.+D^{\prime}\right)$ than

327 Advantageous (C' + D') Decks. Figure 4A shows the Deck selections on each trial for a

328 participant with the median NET 1 to 5 . Half (50.0\%) of participants received the second $\$ 2,000$

329 loan. The amount earned (score minus loan) increased during the Block 1, dropped below zero

330 during Block 3, and was negative by test completion $(-\$ 1,099.58 \pm 191.20$, Min $=-3,015$, Max $=$

331 1,475, Figure 3G).

332 A repeated measures ANOVA on Response Times revealed a main effect of Block

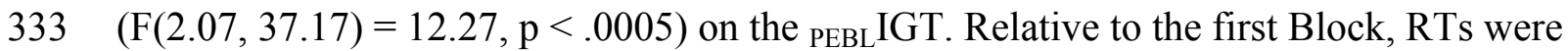

334 significantly shorter on Block $2(t(18)=2.85, p<.02)$, Block $3(t(18)=7.45, p<.0005)$, Block 4

$335(t(18)=4.26, p \leq .0005)$, and Block $5(t(16)=4.59, p<.0005$, Figure 3B). Across all five 
336 Blocks, RTs were equivalent on the PEBLIGT (668.4 + 118.0) and PARIGT (786.4 + 49.1,

$337 \mathrm{t}(24.2)=.92, \mathrm{p}=.37)$. There were more selections from the Disadvantageous than the

338 Advantageous Decks on Block $1(t(18)=2.98, p<.01$, Figure 3D). When collapsing across the

339 five Blocks, over-two thirds (68.4\%) of respondents made more selections from

340 Disadvantageous than Advantageous Decks. Fewer selections were made from Deck A

341 compared to Deck B $(t(18)=4.27, p<.0005)$ or Deck D $(t(18)=2.45, p<.03)$. There was a

342 trend towards more selections on Deck B compared to Deck C $(t(18)=2.05, p=.055$, Figure

343 3F). Figure 4B depicts the Deck selections over the course of the test for a participant with the

344 median NET 1 to 5 . Very few (10.5\%) participants received the second \$2,000 loan.

345 Compensation, defined as the score minus the loan, grew during the Block 1, dropped towards

346 zero in Block 2, and stayed negative for the remainder of the test. A comparison of compensation

347 across platforms (t-test) revealed that the ${ }_{\text {PEBL }}$ IGT money was significantly lower than ${ }_{\text {PAR }}$ IGT

348 during trials 16 to 18 and 23 but higher from trial 74 until test completion ( $-\$ 269.74 \pm 255.93$,

$349 \operatorname{Min}=2,425, \operatorname{Max}=1,950$, Figure 3G). 


\section{DISCUSSION}

352

The PEBL software is becoming a widely-used tool in the social and biomedical sciences

353 (Mueller \& Piper, 2014). Although this widespread use in numerous contexts has helped to

354 establish the general reliability and validity of specific tests, the publication of additional

systematic validation studies comparing their results to existing tests will help establish their

suitability for use in basic research and clinical neuroscience applications, including assessment.

357 This report identifies some procedural similarities, and also differences, between the PEBL and

358

359

360

361

362

363

364

365

366

367

368

369

370

371 Similarly, in a study of twelve children taking the cCPT, Soreni, Crosbie, Ickowicz, and

372 Schachar (2009) found the inter-class correlation (ICC) coefficients for ommission errors: .09; commercial versions of ostensibly equivalent tests.

CPT Tests. The CPT developed by Conners and colleagues has been, and will likely continue to be, an important instrument widely employed for applied and research purposes. The mean RT, variability of RT, omission and commission errors are similar to those reported previously with college students as participants (Burton et al., 2010). Moderate to strong correlations across tests were observed on the CPT measures across platforms. The origin of any inter-test differences is multifaceted and could include procedural details (e.g. software algorithms), interactions between software and hardware, particularly for RTs (Plant \& Quinlan, 2013), or participant variance due to repeated testing. Importantly, the inter-test reliability of the ${ }_{\mathrm{P}} \mathrm{CPT}$ and the ${ }_{\mathrm{C}} \mathrm{CPT}$ are bound by the test-retest reliability of both measures. Previous research has established moderate to high test-retest reliability for the cCPT, in the same range as our inter-test reliability measures. For example, Conners (2004) reported test-retest correlations of 0.55 to 0.84 when the cCPT was administered twice with an inter-test interval of two weeks. 
373 commission errors:.72; RT: .76; and RTSE of .63. In a similar study with 39 children age 6-18

374 over a 3-8 month interval, Zabel et al. (2009) found ICC of .39 and .57 for omission and

375 commission errors, .65 for hit RTs, and .48 for RT variability, concluding that there was

376 substantial variability in these measures even for their large age range. Using a similar go/no-go

377 CPT, Kuntsi et al. (2005), showed for a group of 47 children, inter-class $r$ scores ranged from .7-

378.88 on RT scores; $0.26-.83$ on SD of RT, and .54-.7 on commission errors. Thus, the between-

379 test correlations in our homogeneous sample of college students compared favorably to

380 previously-reported test-retest correspondence scores on CPT tests. Although the experience of

381 the participants was similar when completing the ${ }_{\mathrm{C}} \mathrm{CPT}$ and the ${ }_{\mathrm{P}} \mathrm{CPT}$, some of the algorithms

382 employed in the ${ }_{\mathrm{C}} \mathrm{CPT}$ are unpublished or could not be verified by the authors. This is

383 particularly a concern for the signal detection measures (Stanislaw \& Todorov, 1999) and

384 therefore $d^{\prime}$ and Beta were not compared across platforms. Notably, similarity of intra-test

385 correlations is one criterion for the equivalence of measures (Bartram, 1994). The pattern of

386 results with this sample identified in Table 2 generally supports this criterion for the ${ }_{\mathrm{P}} \mathrm{CPT}$.

387 DS-F and DS-B Tests. DS type tasks have an extensive history and have been

388 implemented in an analogous Highlight to the ${ }_{\mathrm{w}} \mathrm{DS}$ for over a century (Richardson, 2007).

389 Importantly, the test-retest reliability of ${ }_{\mathrm{W}} \mathrm{DS}$ is moderate $(r=.68)$ (Dikmen, Heaton, Grant, \&

390 Temkin, 1999). DS-F did not differ between ${ }_{\mathrm{W}} \mathrm{DS}$ and ${ }_{\mathrm{p}} \mathrm{DS}$. Although DS-B was less than DS-F

391 for the ${ }_{\mathrm{W}} \mathrm{DS}$ and the ${ }_{\mathrm{P}} \mathrm{DS}$, the magnitude of reduction was attenuated on the ${ }_{\mathrm{P}} \mathrm{DS}$. A subset of

392 participants $(\approx 15 \%)$ either were rehearsing the digits aloud or on the keyboard while they were

393 being presented on the ${ }_{\mathrm{P}} \mathrm{DS}$. Use of these strategies could change the fundamental nature of the

394 constructs being measured. It is important to emphasize that although stimuli are present aurally

395 for both the ${ }_{\mathrm{W}} \mathrm{DS}$ and the ${ }_{\mathrm{P}} \mathrm{DS}$, response execution is oral for the ${ }_{\mathrm{W}} \mathrm{DS}$ but typed for the ${ }_{\mathrm{P}} \mathrm{DS}$. The 
396 Highlight of how stimuli is presented and executed is known to produce detectable differences

397 (Karakas et al., 2002). The correlation between the ${ }_{\mathrm{p}} \mathrm{DS}$ and the ${ }_{\mathrm{W}} \mathrm{DS}$ was only moderate. This

398 could be due to modality effects or the use of a college-aged sample may have resulted in a

399 restriction of range which attenuated the associations. In principle, voice recognition algorithms

400 would make ${ }_{\mathrm{W}} \mathrm{DS}$ and ${ }_{\mathrm{P}} \mathrm{DS}$ more similar, and an alternative to self-administration is to have a

401 researcher or clinician enter the responses for the study participant, so that he or she must

402 respond vocally. Other investigators that are refining this technology have identified moderate

403 correlations across modalities (Forward $=.48$, Backward $=.50$ ) but difficulties recognizing the

404 responses of participants with accents is not trivial (Miller et al., 2014). More generally, perhaps

405 the notion of the ${ }_{\mathrm{W}} \mathrm{DS}$ as the "gold standard" is questionable. Computerized administration offers

406 the potential of delivering stimuli at a more consistent rate, intensity, and clarity than traditional

407 methods (Woods et al., 2011). The use of more trials per number of digits and alternative

408 procedures for advancement to the difficulty threshold may improve the precision of DS

409 measurement.

410 IGT Tests. The IGT is sometimes described as a "one-shot" measure of executive

411 function. Several laboratories have identified significant practice effects on the IGT (Bechara, et

412 al., 2000a; Bull, et al., 2015; Fernie \& Tumney, 2006; Fontaine et al. 2015; Piper et al. 2015a;

413 Verdejo-Garcia et al. 2007). As such, the primary goal of this investigation was not to attempt to

414 evaluate correlations between the ${ }_{\text {PEBL }}$ IGT and the ${ }_{\text {PAR }}$ IGT and instead examined response

415 patterns within each test. The ${ }_{\text {PEBL }}$ IGT and the ${ }_{\text {PAR }}$ IGT have many procedural similarities but also

416 some differences (Table 1) which may not be widely appreciated. Although there were

417 pronounced individual differences, the ${ }_{\text {PAR }}$ CPT percentiles were well different than fifty for this

418 collegiate sample. On the primary dependent measure (deck selections), there was a high degree 
419 of similarity between the ${ }_{\mathrm{PAR}} \mathrm{IGT}$ and ${ }_{\mathrm{PEBL}} \mathrm{IGT}$. For example, the development across trials for a

420 preference of Advantageous over Disadvantageous Decks was evident with both tests (Figure 2C

$421 \& 2 \mathrm{D})$. The choice of individual decks (e.g. Deck B was twice as commonly selected as Deck A)

422 was identified with the ${ }_{\text {PAR }}$ IGT and the ${ }_{\text {PEBL }}$ IGT (Figure 2E \& 2F). Response times across blocks

423 were virtually identical in both computerized platforms (Figure 2A \& 2B). However, the

424 compensation awarded at the end of the test, a secondary measure (Bechara, 2007), was

425 examined to identify any impact of the procedural differences in Table 1. Overall, compensation

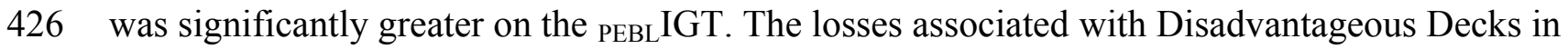

427 the ${ }_{\text {PEBL }}$ IGT (Deck B $\left.=-\$ 1,250\right)$ are much less pronounced than those in the ${ }_{\text {PAR }}$ IGT punishments

428 (Deck B starts at $-\$ 1,250$ but increases up to $-\$ 2,500$ ). Although this procedural difference did

429 not produce other pronounced effects in this sample, future versions of PEBL will allow the

430 experimenter to select among the original (A B C D) IGT (Bechara et al., 1994) or the variant

431 (A' B' C' D') task (Bechara et al., 2000a). Due to this key methodological difference, results

432 from the ${ }_{\text {PEBL }}$ IGT (Hawthorne, Weatherford, \& Tochkov, 2011; Lipnicki, et al., 2009a, 2009b)

433 are unlikely to be identical to what would be obtained if the PAR IGT was employed.

434 These datasets also provided an opportunity to identify substantial individual differences

435 with both the ${ }_{\mathrm{PAR}} \mathrm{IGT}$ and the ${ }_{\mathrm{PEBL}} \mathrm{IGT}$. One concern with quantifying decision making with the

436 IGT is that there is considerable heterogeneity of responding, even by normal (i.e. neurologically

437 intact) participants (Steingroever et al., 2013). For example, Carolselli and colleagues

438 determined that over two-thirds (69.5\% versus $68.4 \%$ in the present study) of university students

439 completing an IGT based on Bechara et al., (1994) made more selections from Disadvantageous

440 than Advantageous Decks (Caroselli et al., 2006). A similar pattern with the ${ }_{\text {PAR IGT was also }}$

441 identified in a separate sample with $70.3 \%$ of college students from the southwestern U.S. again 
442 choosing Disadvantageous over Advantageous Decks (Piper et al., 2015b). If forced to choose

443 whether the median participants in this college student sample (Figure 4) show a response pattern

444 more similar to the typical control or to a patient (EVR 318) from Bechara et al. 1994, we would

445 select the lesioned profile. Similarly, Bechara and colleagues noted that over one-third (37\%) of

446 controls fell within the range of ventromedial prefrontal lesion group when using the ascending

447 (A' B' C' D') paradigm (Bechara \& Damasio, 2002). Findings like this, as well as the present

448 outcomes (i.e. almost half favoring the Disadvantageous Decks with the ${ }_{\mathrm{PAR}} \mathrm{IGT}$ ) call into

449 question the clinical utility of this test (see also the meta-analysis by Steingroever et al. 2013).

450 The IGT is likely measuring important elements of executive function but we are skeptical that

451 preferential selections from Disadvantageous Decks is a specific index of a brain insult.

452 The benefit of open-source neurobehavioral tests like the PEBLIGT is that the source code

453 is readily available (see supplemental materials) and anyone, independent of their financial

454 resources, can use PEBL. This contributes to the democratization of science. It must also be

455 emphasized that there is substantial room for improved construct validity and test-retest

456 reliability for the IGT (Buelow \& Suhr, 2009). Anyone, even with limited computer

457 programming expertise, who is interested in modifying task parameters and generating future

458 generations of decision making paradigms may do so, which, hopefully, will result in tests that

459 have even better psychometric properties (e.g. the new peBLIGT by Bull, et al., 2015). The

460 transparency and flexibility of PEBL are advantages over proprietary computerized

461 neurobehavioral applications. Full disclosure of all methodological inHighlightion including the

462 underlying programming of computerized neurobehavioral tests is consistent with the

463 dissemination policy of the National Science Foundation (NSF, 2015) and others. However, the

464 modifiability of PEBL is a bit of a double-edged sword in that tasks like the IGT have undergone 
465 substantial refinement over the past decade. At a minimum, investigators that make use of PEBL,

466 PAR, or other applications must include in their methods sections the version of the software

467 they utilized.

468 One potential limitation of this report is the samples consisted primarily of young adult

469 college students, whereas in clinical settings, these tests are used across the lifespan (children to

470 adult) with a broad range of educational and mental, and psychological profiles. However, a

471 restriction of range for the dependent measures (see Table 2 and the range of the Minimum and

472 Maximum on both ${ }_{\text {PAR }}$ IGT and ${ }_{\mathrm{W}} \mathrm{DS}$ ) does not appear to be an appreciable concern for this

473 dataset, possibly because both cohorts included some individuals with ADHD, including ones

474 not currently taking their stimulant medications. As noted earlier, the characteristics of this

475 convenience sample is more comparable to those employed by others (Caroselli et al. 2006).

476 The PEBL software currently consists of over one-hundred tests of motor function, attention,

477 learning, memory, and executive function in many different languages, and so additional

478 validation studies with more diverse (age, ethnicity, socioeconomic status, computer experience)

479 samples are warranted. Second, the sample size ( $N=44$ to $47 /$ cohort) was sufficient to identify

480 correlations across platforms $\left(\mathrm{r}_{\text {crit }}>.20\right)$. However, this number of participants is on the low-end

481 to identify correlation differences (Table 3 or the $95 \%$ CI of noted correlations) between

482 applications. Additional, and better powered, IGT psychometric investigations are needed which

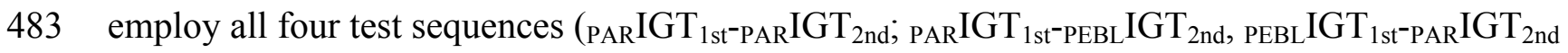

484 PEBL $\mathrm{IGT}_{1 \mathrm{st} \mathrm{PEBL}^{-}} \mathrm{IGT}_{2 \mathrm{nd}}$ ) for test development. Third, the PDS was modified so that numbers were 485 presented only via audio. These findings on the criterion validity of the PDS with the WDS may 486 not be applicable to different modes (e.g. visual only, or visual and auditory) of stimuli delivery.

487 Possibly, a fourth limitation is the few procedural differences between the ${ }_{\text {PAR }}$ IGT and ${ }_{\text {PEBL }}$ IGT 
488 (Table 1) were not identified until after the data had been collected. Identification of all the 489 essential procedural variables for proprietary measures is not trivial, nor is that even a goal for 490 PEBL test development. Future releases of PEBL (0.15) will however contain an IGT based on 491 the Bechara et al. 2000b as well as other procedural variations (Bull, et al., 2015).

\section{Conclusions}

493 This report identified a high degree of consistency between the ${ }_{\mathrm{C}} \mathrm{CPT}$ and ${ }_{\mathrm{P}} \mathrm{CPT}$, the ${ }_{\mathrm{W}} \mathrm{DS}$ 494 and the ${ }_{\mathrm{P}} \mathrm{DS}$ Forward, and the ${ }_{\mathrm{PAR}} \mathrm{IGT}$ and ${ }_{\mathrm{PEBL}} \mathrm{IGT}$. Further procedural refinements in this open495 source software battery will continue to enhance the utility of the PEBL to investigate individual 496 differences in neurocognition. 
499 Thanks to Shawn Ell, PhD and members of the Ell lab for use of their laboratory space. Frank

500 Barton provided technical assistance. Shelbie Wolfe and Samantha Munson assisted in data

501 collection. Melissa A. Birkett, PhD and Peter N. Bull, MSc provided feedback on earlier versions 502 of this manuscript.

503

504

505 
Aggarwal R, Mishra A, Crochet P, Sirimanna P, \& Darzi A. 2011. Effect of caffeine and taurine on simulated laparoscopy performed following sleep deprivation. British Journal of Surgery, 98:1666-1672. doi: 10.1002/bjs.7600.

\section{3}

Anderson VE, Siegel FS, Fisch RO, Wirt RD. 1969. Responses of a Phyenylketonuric children on a continuous performance test. Journal of Abnormal Psychology, 74: 358-362.

Bartram D. 1994. Computer-based assessment. In C. L. Cooper \& I. T. Robertson (Eds.), International Review of Industrial and Organizational Psychology (Vol. 9, pp. 31-69). Chichester, England: Wiley.

Bechara A. 2007. Iowa Gambling Task Professional Manual. Psychology Assessment Resources, Lutz: FL.

Bechara A, Damasio AR, Damasio H, Anderson SW. 1994. Insensitivity to future consequences following damage to human prefrontal cortex. Cognition, 50: 7-15.

Bechara A, Damasio H. 2002. Decision-making and addiction (part I): Impaired activation of somatic states in substance dependent individuals when pondering decisions with negative future consequences. Neuropsychologia, 40: 1675-1689.

525 Bechara A, Tranel D, Damasio, H. (2000b). Characterization of the decision-making deficit of patients with ventromedial prefrontal cortex lesions. Brain, 123: 2189-2202.

527 Birkett MB, Averett A, Soni J, Piper B. 2015. The influence of visual and auditory cue salience 
on Iowa Gambling Task performance. Poster presented at the American Psychological Association.

530 Buelow MT, Surh JA. 2009. Construct validity of the Iowa Gambling Task. Neuropsychology 531 Review, 19: 102-114. doi: 10.1007/s11065-009-9083-4.

532 Bull PN, Tippett LJ, Addis DR. 2015. Decision making in healthy participants on the Iowa Gambling Task: new insights from an operant approach. Frontiers in Psychology, 6, 391. doi: 10.3389/fpsyg.2015.00391.

Burton L, Plaff D, Bolt N, Hadjkyriacou D, Silton N, Killgallen C, J Coffer, Allimant J. 2010. Effect of gender and personality on the Conners Continuous Performance Test. Journal of Clinical and Experimental Neuropsychology, 32: 66-70. doi:10.1080/13803390902806568

Caroselli JS, Hiscock M, Scheibel RS, Ingram, F. 2006. The simulated gambling paradigm applied to young adults: An examination of university students' performance. Applied Neuropsychology, 13: 203-212.

544 Cohen AL, Shapiro SK. 2007. Exploring the performance differences on the flicker task and the

Clark DG, Kar J. 2011. Bias of quantifier scope interpretation is attenuated in normal aging and semantic dementia. Journal of Neurolinguistics, 24: 411-9.

547 Conners CK. 2004. Multi Health Systems. Conners' Continuous Performance Test II:

548 Technical guide for software manual. New York: Multi-Health Systems.

549 Conners K, Jeff JL. 1999. ADHD in adults and children: The latest assessment and treatment $550 \quad$ strategies. Kansas City, MO: Compact Clinicals. 
551 Danckert J, Stöttinger E, Quehl N, Anderson B. 2012. Right hemisphere brain

552 damage impairs strategy updating. Cerebral Cortex, 22: 2745-2260. doi:

553 $10.1093 /$ cercor/bhr351

554

555

556

557

558

559

560

561

562

563

564

565

566

567

568

569

570

571

572

573

Dikmen SS, Heaton RK, Grant I, Temkin NR. 1999. Test-retest reliability and practice effects of the expanded Halstead-Reitan Neuropsychological Test Battery. Journal of the International Neuropsychological Society, 5: 346-336.

Dougherty DM, Marsh DM, Mathias CW. 2002. Immediate and delayed memory tasks: A computerized behavioral measure of memory, attention, and impulsivity. Behavior Research Methods, 34: 391-398.

Earle-Boyer EA, Serper MR, Davidson M, Harvey PD.1991. Continuous performance tests in schizophrenic patients: Stimulus and medication effects on performance. Psychiatry Research, 37: 47-56.

Fernie G, Tumney RJ. 2006. Some decks are better than others: The effect of reinforcer type and task instructions on learning in the Iowa Gambling Task. Brain \& Cognition, 60: 94-102.

Fontaine A, Piper B, Mueller S, Coane J. 2015. Test-retest reliability of PEBL executive control tasks in younger and older adults. Poster presented at the annual meeting of the Psychonomic Society.

Fox CJ, Mueller ST, Grey HM, Raber J, Piper BJ. 2013. Evaluation of a short-form of the Berg Card Sorting test. PLoS One, 8(5): e63885. doi: 10.1371/journal.pone.0063885.

González-Giraldo Y, Rojas J, Novoa P, Mueller ST, Piper BJ, Adan A, Forero DA. 2014. Functional polymorphisms in BDNF and COMT genes are associated with objective differences in arithmetical functioning in a sample of young adults. Neuropsychobiology, 70: 152-157. doi: 10.1159/000366483. 
574 Greenberg LM, Waldman ID. 1993. Developmental normative data on the Test of Variables of

575 Attention (T.O.V.A. ${ }^{\mathrm{TM}}$ ). Journal of Child Psychology \& Psychiatry, 34: 1019-1030.

576 Hawthorne MJ, Weatherford DR, Tochkov K. 2011. Effects of explicit and implicit cognitive

577 factors on the learning patterns in the Iowa Gambling Task. American Journal of $578 \quad$ Psychological Research, 7: 64-78.

579 Homack S, Riccio CA. 2006. Conners' Continuous Performance Test (2nd ed.; CCPT-II). $580 \quad$ Journal of Attention Disorders, 9:556-558.

581 Karakas S, Yalm A, Irak M, Erzengin OU. 2002. Digit span changes from puberty to old age 582 under different levels of education. Developmental Neuropsychology, 22: 423-453.

583 Keneko H, Yoshikawa T, Nomura K, Ito H, Yamauchi H, Ogura M, Honjo S. 2011.

584 Hemodynamic changes in the prefrontal cortex during Digit span task: A Near-Infrared 585 Spectroscopy study. Neuropsychobiology, 63: 59-65. doi: 10.1159/000323446.

586 Kuntsi J, Andreou P, Ma J, Börger NA, van der Meere JJ. 2005. Testing assumptions for 587 endophenotype studies in ADHD: reliability and validity of tasks in a general population sample. BMC Psychiatry 5: 40. doi:10.1186/1471-244X-5-40.

589 Lezak MD, Howieson DB, Bigler ED, Tranel D. 2012. Neuropsychological Assessment (5th ed), $590 \quad$ New York: Oxford.

591 Lipnicki DM, Gunga HC, Belavy DL, Felsenberg D. 2009a. Decision making after 50 days of 592 simulated weightlessness. Brain Research, 1280: 84-89. doi:

593 10.1016/j.brainres.2009.05.022.

594 Lipnicki DM, Gunga HC, Belavý DL, Felsenberg D. 2009b. Bed rest and cognition: effects on 595 executive functioning and reaction time. Aviation Space \& Environmental Medicine, 80: $1018-24$. 
597 Lynn R, Irwing P. (2008). Sex differences in mental arithmetic, digit span, and g

598 defined as working memory capacity. Intelligence, 36: 226-235.

599 Lyvers M, Tobias-Webb J. 2010. Effects of acute alcohol consumption on executive cognitive 600 functioning in naturalistic settings. Addictive Behavior, 35: 1021-28.

601 Mackworth NH. 1948. The breakdown of vigilance during prolonged visual search. Quarterly $602 \quad$ Journal of Experimental Psychology, 1: 6-21.

603 McGee RA, Clark SE, Symons DK. 2000. Does the Conners' Continuous performance test aid in 604 ADHD diagnosis? Journal of Abnormal Child Psychology, 28: 415-424.

605 Miller DI, Talbot V, Gagnon M, Messier C. 2013. Administration of neuropsychological tests 606 using interactive voice response technology in the elderly: Validation and limitations. $607 \quad$ Frontiers in Neurology, 4: 107. doi: 10.3389/fneur.2013.00107.

608 Mueller ST. 2012. The PEBL Manual, Version 0.13. Lulu Press. ISBN 978-0557658176.

609 Mueller ST. 2015. The Psychology Experiment Building Language, Version 0.14. Retrieved 610 from http://pebl.sourceforge.net.

611 Mueller ST, Piper BJ. 2014. The Psychology Experiment Building Language (PEBL) and PEBL 612 test battery. Journal of Neuroscience Methods, 222: 250-259.

613 doi:10.1016/j.jneumeth.2013.10.024.

614 National Science Foundation 2015. Dissemination and sharing of research results. Accessed 615 7/22/2015 at: http://www.nsf.gov/bfa/dias/policy/dmp.jsp

616 Ogg RJ, Zou P, Allen DN, Hutchins SB, Dutkiewicz RM, Mulhern RK. 2008. Neural correlates 617 of a clinical continuous performance test. Magnetic Resonance Imaging, 26: 504-512.

618 Paul RH, Lawrence J, Williams LM, Richard CC. 2005. Preliminary validity of "Integneuro"TM": 
A new computerized battery of neurocognitive tests. International Journal of Neuroscience, 115:1549-1567.

621 Peterson DS, Fling BW, Mancini M, Cohen RG, Nutt JG, Horak FB. 2015. Dual-task interference and brain structural connectivity in people with Parkinson's disease who freeze. Journal of Neurology, Neurosurgery \& Psychiatry, 86: 786-792.

Piper BJ. 2010. Age, handedness, and sex contribute to fine motor behavior in children. Journal of Neuroscience Methods, 195: 88-91. doi: 10.1016/j.jneumeth.2010.11.018.

Piper BJ, Acevedo SF, Craytor MJ, Murray PW, Raber J. 2010. The use and validation of the spatial navigation Memory Island test in primary school children. Behavioural Brain Research, 210: 257-262. doi: 10.1016/j.bbr.2010.02.040.

Piper BJ, Acevedo SF, Kolchugina GK, Butler RW, Corbett SM, Honeycutt EB, Craytor MJ, Raber J. 2011. Abnormalities in parentally rated executive function in

Piper BJ, Mueller ST, Geerken AR, Dixon KL, Kroliczak G, Olsen RHJ, Miller JK. 2015 a. Reliability and validity of neurobehavioral function on the Psychology Experimental Building Language test battery in young adults. PeerJ 3:e1460; doi: 10.7717/peerj.1460. comparison of the Psychological Assessment Resources and the PEBL versions of the Iowa Gambling Task in young-adults. Psychology Experiment Building Language Technical Report Series, 2015-01. Retrieved from http://sites.google.com/site/pebltechnicalreports/home/2015/pebl-technical-report-201501. 
642 Piper BJ, Li V, Eowiz M, Kobel Y, Benice T, Chu A, Olsen RH, Rice DZ, Gray HM, Mueller 643 ST, et al. 2012. Executive function on the Psychology Experiment Building Language 644 test battery. Behavior Research Methods, 44: 110-123. doi: 10.3758/s13428-011-0096-6.

645 Plant RR, Quinlan PT. 2013. Could millisecond timing errors in commonly used equipment be a 646 cause of replication failure in some neuroscience studies? Cognitive Affective \& Behavioral Neuroscience 13: 598-614. doi: 10.3758/s13415-013-0166-6.

Richardson JT. 2007. Measures of short-term memory: A historical review. Cortex, 43: 635-650.

Riccio CA, Reynolds CR, Lowe P, Moore JT. 2002. The continuous performance test: A window on the neural substrates for attention. Archives of Clinical Neuropsychology, 17: 235-272.

Rosvold HE, Mirsky AF, Sarason I, Bransome ED, Beck LH. 1956. A continuous performance test of brain damage. Journal of Consulting Psychology, 20: 343-350.

Solanto M, Newcorn J, Vail L, Gilbert S, Ivanov I, Lara R. 2009. Stimulant drug response in the

Soreni N, Crosbie J, Ickowicz A, Schachar R 2009. Stop signal and Conners' continuous predominantly inattentive and combined subtypes of Attention-Deficit/Hyperactivity Disorder. Journal of Child and Adolescent Psychopharmacology, 19: 663-671. doi: performance tasks: test--retest reliability of two inhibition measures in ADHD children. Journal of Attention Disorders, 13(2): 137-143. doi: 10.1177/1087054708326110.

St Clair-Thompson HL, Allen RJ. 2013. Are forward and backward recall the same? A dual-task study of digit recall. Memory \& Cognition, 41(4): 519-532. doi: 10.3758/s13421-012-0277-

662 2.

663 Stanislaw H, Todorov N. 1999. Calculation of signal detection theory measures. Behavior 664 Research Methods, Instruments, \& Computers, 31: 137-149. 
665 Steingroever H, Wetzels R, Horstman A, Neumann J, Wagenmakers EJ. 2013. Performance of 666 healthy participants on the Iowa Gambling Task. Psychological Assessment, 25: 180-193. 667 doi: $10.1037 / \mathrm{a} 0029929$.

668 Verdejo-Garcia A, Benbrook A, Funderburk F, David P, Cadet JL, Bolla KI. 2007. The 669 differential relationship between cocaine use and marijuana use on decision-making 670 performance over repeated testing with the Iowa Gambling Task. Drug \& Alcohol 671 Dependence, 90: 2-11.

672 Wardle MC, Hart AB, Palmer AA, de Wit H. 2013. Does COMT genotype influence the effects 673 of d-amphetamine on executive functioning? Genes, Brain and Behavior, 12: 13-20. doi: 10.1111/gbb.12012.

Woods DL, Kishiyama MM, Yund EW, Herron TJ, Edwards B, Poliva O, Hink RF, Reed B.

676 2011. Improving digit span assessment of short-term verbal memory. Journal of Clinical and Experimental Neuropsychology, 33: 101-111. doi: 10.1080/13803395.2010.493149.

678 Zabel, TA, von Thomsen, C, Cole, C, Martin, R, Mahone, EM (2009). Reliability concerns in the 679 repeated computerized assessment of attention in children. The Clinical $680 \quad$ Neuropsychologist, 23(7), 1213-1231. 
682

683

684

685

686
Figure 1. Scatterplots depicting the association between measures on the Psychology Experiment Building Language and the Conner's Continuous Performance Test including reaction time (top: $r(42)=+.78,95 \% \mathrm{CI}=.63$ to $.87, p<.0005$ ), omission errors (middle: $r_{P}(42)=+.65,95 \% \mathrm{CI}=.44$ to $\left..79, p<.0005\right)$ and commission errors (bottom: $r(42)=$ $+.66,95 \% \mathrm{CI}=.45$ to $.80, p<.0005)$.
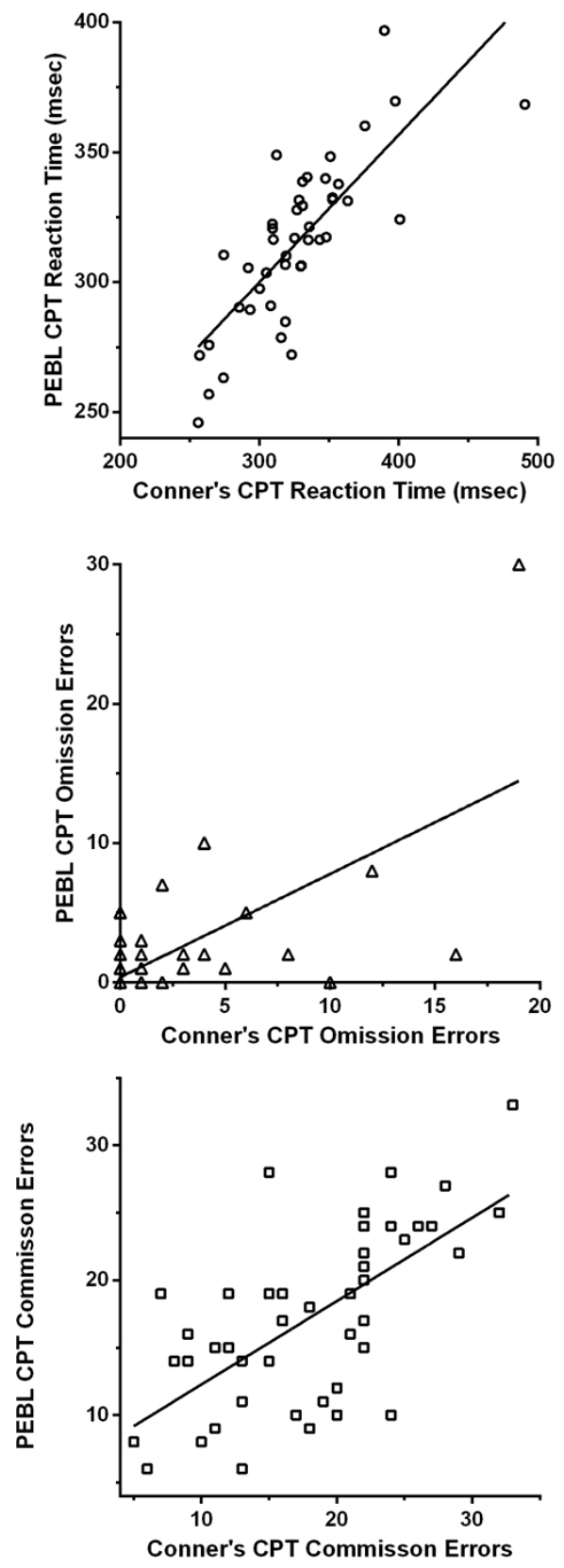
689 Figure 2. A) Wechsler (W) and Psychology Experiment Building Language (P) Digit Span 690 Forward (Fwd) and Backward (Bwd). ${ }^{\mathrm{A}} p<.0005$ versus Digit Span Forward, ${ }^{\mathrm{B}} p<.0005$ versus 691 PEBL Digit Span Forward. B) Scatterplot of Wechsler by PEBL Digit Span total $\left(r_{P}(45)=.56\right.$, $69295 \% \mathrm{CI}=.31$ to $.74, p<.0005)$.

A. Mean Digit Span

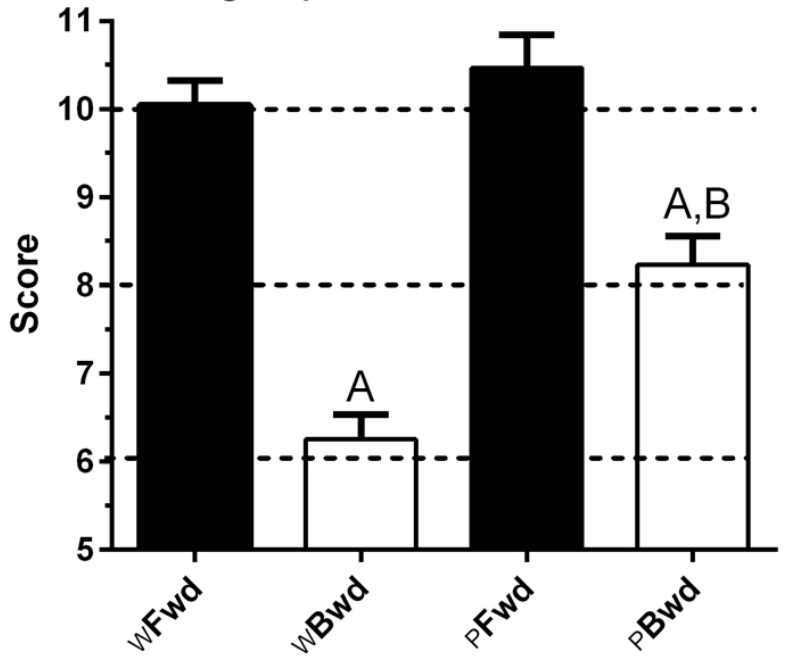

B. Digit Span scatterplot

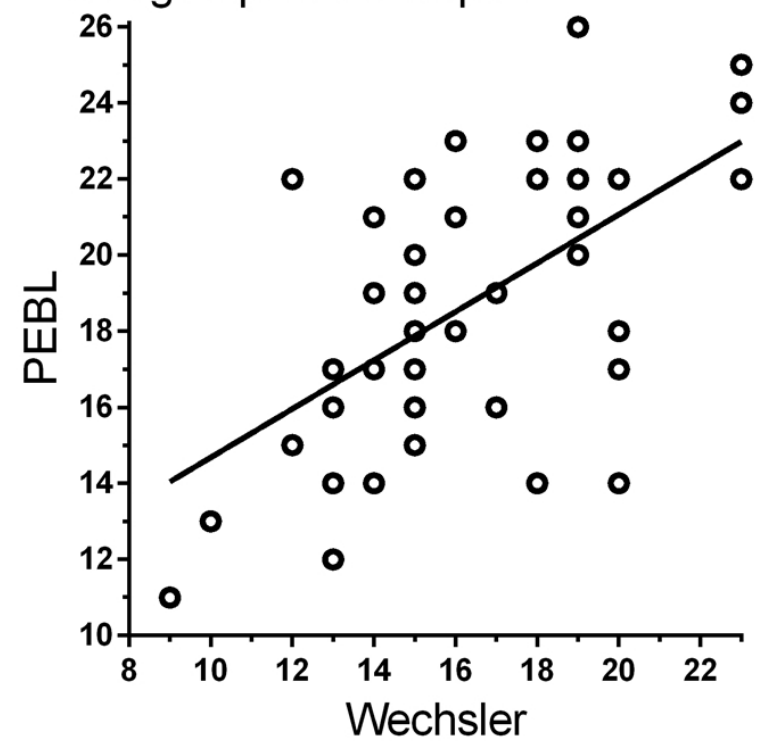


694 Figure 3. Response times on the Psychological Assessment Resources (PAR, A) and Psychology 695 Experiment Building Language (PEBL, B) Iowa Gambling Task by block of 20 trials ( ${ }^{*} p<$ 696 .0005). Selection of advantageous and disadvantageous decks (C, D) $\left({ }^{*} p<.05\right.$ versus

697 disadvantageous on block 1). Selection of each deck (E, F) ( ${ }^{A} p<.005$ versus Deck B, C, or D; $698{ }^{\mathrm{B}} p<.05$ versus Deck C and D; ${ }^{\mathrm{C}} p<.05$ versus Deck B). Compensation by trial (G) (horizontal 699 line indicates $p<.05)$. 

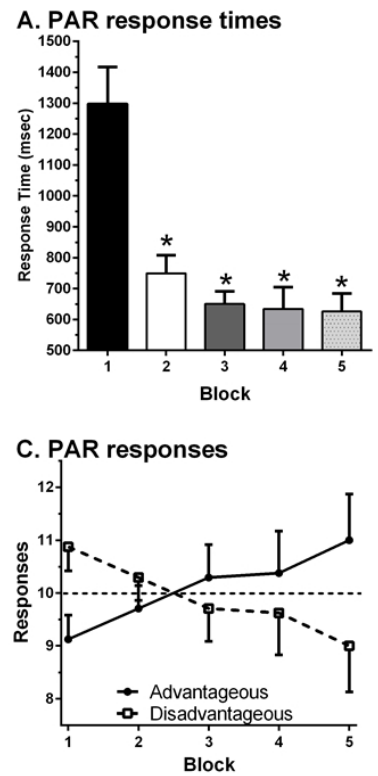

E. PAR deck selections

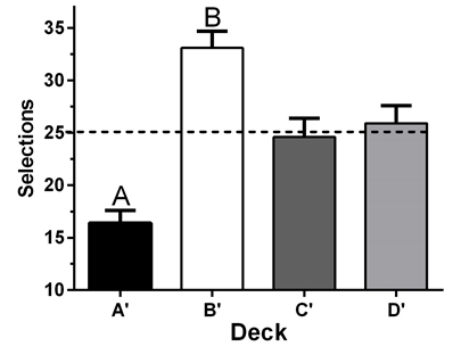

G. Score minus loan

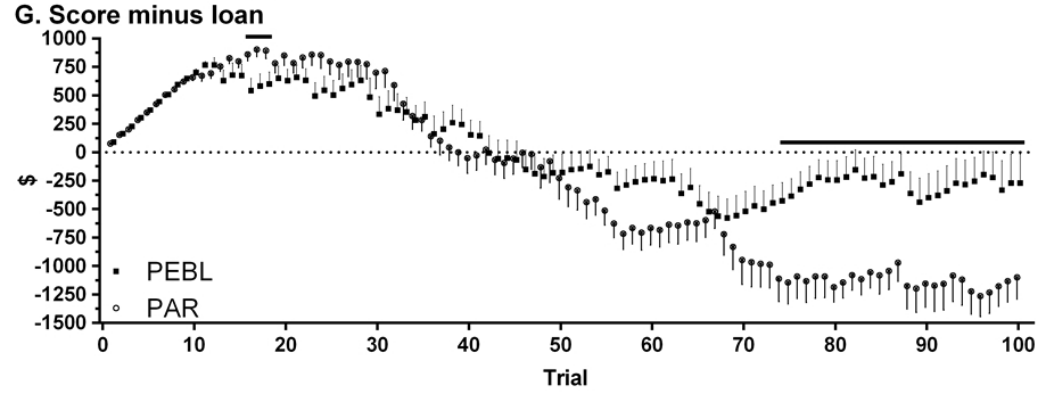

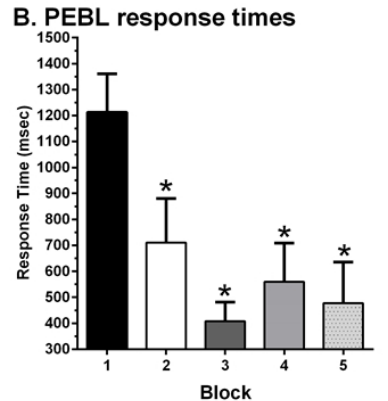

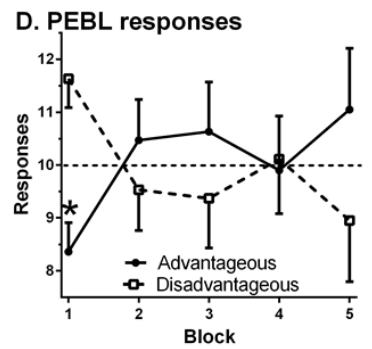

F. PEBL deck selections

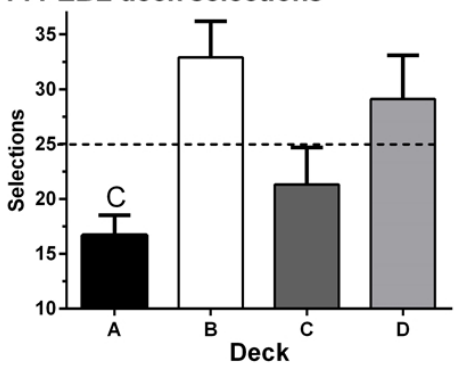

701 Figure 4. Deck selections over one-hundred trials for the participant (a 34 year-old, Native

702 American female) with the median NET1 to 5 (0) on the Psychological Assessment Resources

703 (PAR) Iowa Gambling Task (A). Deck selections for the participant (a 18 year-old Native

704 American male) with the median NET1 to $5(-2)$ on the Psychology Experiment Building

705 Language (PEBL) Iowa Gambling Task (B). 


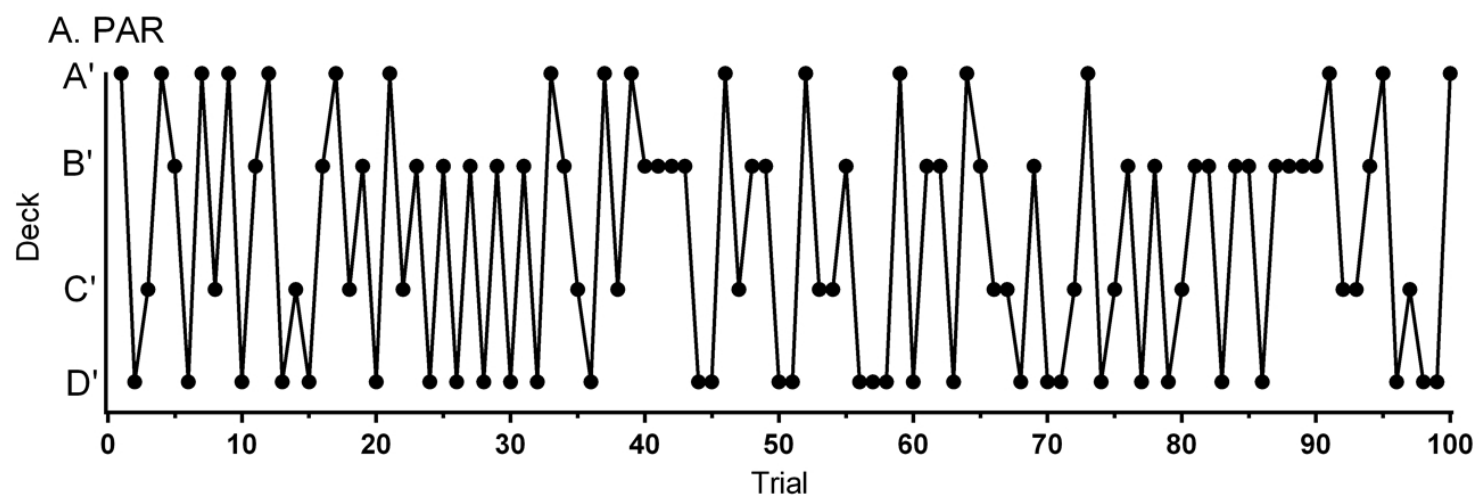

B. PEBL

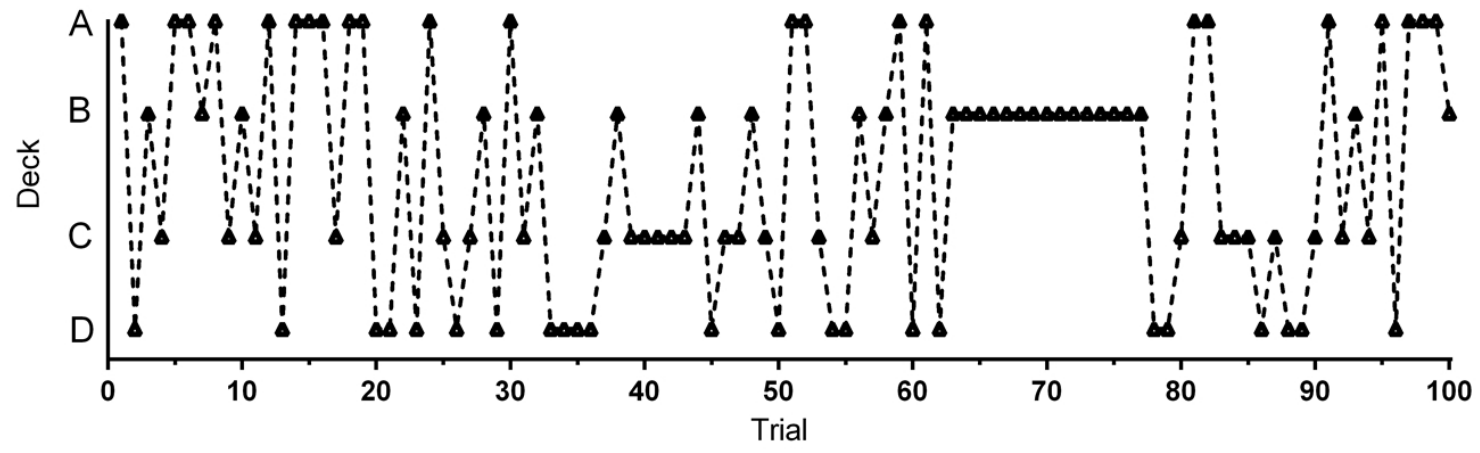


Table 1. A comparison of the Bechara IGT distributed by Psychological Assessment Resources (PAR) and the Mueller and Bull IGT

distributed with version 0.14 of the Psychology Experiment Building Language (PEBL).

\begin{tabular}{|c|c|c|}
\hline & $\underline{\text { PAR }}$ & $\underline{\text { PEBL }}$ \\
\hline Instructions (words) & 441 & 379 \\
\hline Visual post-trial feedback & yes & yes \\
\hline Auditory post-trial feedback & yes & yes \\
\hline Post-trial wait period & yes & yes \\
\hline Deck A: Reward (\$) & $80,90,100,110,120,130,140,150,160,170$ & 100 \\
\hline Deck A: Punishment (\$) & $150,200,250,300,350$ & $150,200,300,350$ \\
\hline Deck B: Reward (\$) & $80,90,100,110,120,130,140,150,160,170$ & 100 \\
\hline Deck B: Punishment (\$) & $1,250,1,500,1,750,2000,2,250,2500$ & 1,250 \\
\hline Deck C: Reward (\$) & $40,45,50,55,60,65,70,75,80,85,90,95$ & 50 \\
\hline Deck C: Punishment (\$) & $25,50,75$ & $25,50,75$ \\
\hline Deck D: Payoff (\$) & $40,45,50,55,60,65,70,75,80,85,90,95$ & 50 \\
\hline Deck D: Loss (\$) & $250,275,300,350,275$ & 250 \\
\hline Trials & 100 & 100 \\
\hline Cards/deck (maximum) & 60 & 100 \\
\hline Standardized $\left(\mathrm{T}_{50}\right)$ scores & yes & no \\
\hline Cost & $\$ 560^{\mathrm{P}}$ & $\$ 0$ \\
\hline
\end{tabular}




\section{PeerJ}

739 PPrice in U.S.D. on $1 / 1 / 2016$. 
740

741 Table 2. Age and sex corrected percentiles of the participants $(\mathrm{N}=44)$ on the Conner's

742 Continuous Performance Test. SE: standard error.

743

744

$\underline{\text { Min }}$

$\underline{\operatorname{Max}}$

$\underline{\text { Mean }}$

$\underline{\text { SEM }}$

745 Reaction time

1.0

94.2

18.6

2.9

746 Reaction time SE

1.0

99.0

44.3

5.0

747 Omissions

20.8

99.0

47.5

3.7

748 Commissions

19.0

99.0

74.4

3.7

749 d'

10.9

97.3

69.6

3.3

$750 \quad B$

24.7

78.1

36.0

1.6

751

752 
753

754 Table 3. Intra-test Continuous Performance Test Spearman correlations (Conners/PEBL).

$755{ }^{\mathrm{a}} p<.05$.

756

757

A.

B.

C.

758 A. Reaction-Time (msec) +1.00

759

B. Reaction-Time SE

$+0.54^{\mathrm{a}} /+0.18$

$+1.00$

760

C. Omission Errors

$+0.20 /+0.03$

$+0.53^{\mathrm{a} /}+0.35^{\mathrm{a}}$

$+1.00$

761

D. Commission Errors

$-0.38^{\mathrm{a}} /-0.36^{\mathrm{a}}$

$+0.16 /+0.29$

$+0.32^{\mathrm{a} /+0.36^{\mathrm{a}}}$

762 
763 Supplementary Figure 1. Scatterplot showing the association of variability of response times on

764 the Conner's and the Psychology Experiment Building Language (PEBL) Continuous

765 Performance Tests (CPT) among college student participants $(\mathrm{N}=44)$. Removal of one extreme

766 score (upper-right) reduced the proportion of variation accounted considerably $\left(\mathrm{R}^{2}=.44, p<\right.$

767.0005 to $\left.\mathrm{R}^{2}=.04, p=.19\right)$.

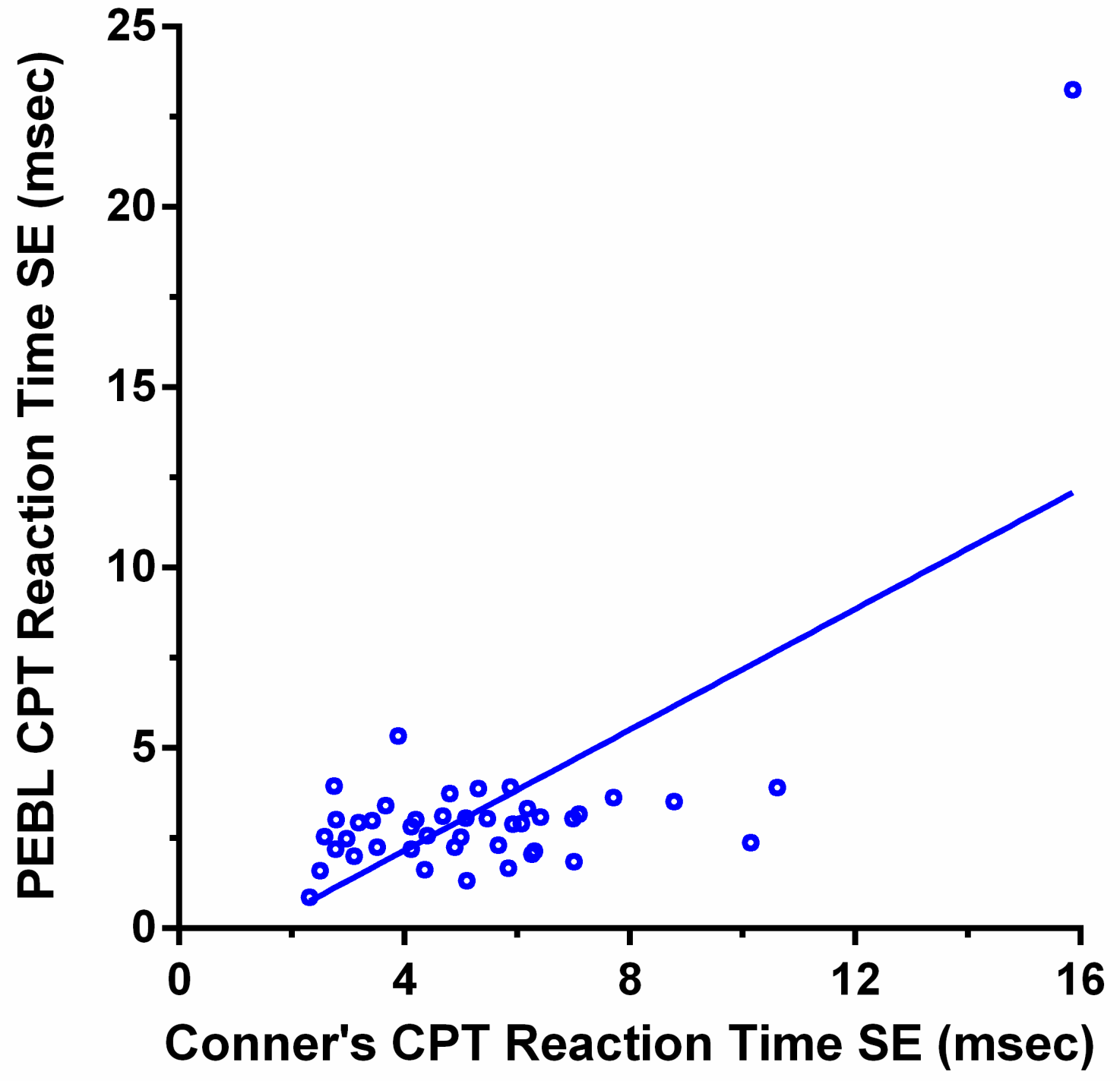

